\title{
Predictors of Job Satisfaction among Emerging Adults in Alberta, Canada
}

\author{
Abu Sadat Nurullah \\ Department of Sociology, University of Alberta \\ 5 - 21 Tory Building, Edmonton, Alberta, Canada T6G 2H4 \\ Tel: 780-716-1305 E-mail: nurullah@ualberta.ca
}

The data used in this paper were collected by the Population Research Laboratory (PRL), University of Alberta, as part of the School-Work Transition Project directed by Dr. H. Krahn and Dr. G. S. Lowe. The survey was funded by Alberta Learning.

\begin{abstract}
This study explores the aspect of satisfaction with jobs and career, and the predictors of job satisfaction among the emerging adults in Alberta. Obtaining data from the 2003 Alberta High School Graduate Survey among a sample of 1,030 emerging adults from Alberta, the paper examines the predictors of job satisfaction among the emerging adults, which are self-esteem, happiness, work-reward preferences, valued job characteristics, income, education, occupational categories, and other demographic variables. Using structural equation modeling, a job satisfaction model has been developed. The findings indicate that self-esteem and valued job characteristics are direct and strongest predictors of job satisfaction among the emerging adults. In addition, happiness and income positively predicts job satisfaction. The variable 'work-reward preferences' does not directly predict job satisfaction, but is rather mediated through self-esteem and valued job characteristics. Discussion includes limitation, future research direction, and policy implications.
\end{abstract}

Keywords: Job satisfaction, Self-Esteem, Happiness, Work-Reward preferences, Valued job characteristics, Income

\section{Introduction}

Over the last several decades, numerous studies have been conducted around the world examining the impact of different psycho-socio-economic factors on job satisfaction. Research on job satisfaction has examined the role of self-esteem (Alavi \& Askaripur, 2003; Salmela-Aro \& Nurmi, 2007; Sekaran, 1986), gender (Clark, 1997; Dole \& Sehroeder, 2001; Donohue \& Heywood, 2004; Eskildsen, Kristensen, \& Westlund, 2004; Haviland, 2004; Kim, 2005; Manning, 2002; Oshagbemi, 2000; Okpara, 2004), education (Okpara, 2004), income (Sokoya, 2000; Sweeney, McFarin, \& Inderrieden, 1990) and happiness (Boehm \& Lyubomirsky, 2008; Connolly \& Viswesvaran, 2000; Judge \& Ilies, 2004). In 1992, Cranny, Smith, and Stone asserted that more than 5,000 studies of job satisfaction have been published. However, only a few academic research (if any) focused on the predictors of job satisfaction among emerging adults in Canada, and particularly in Alberta. Therefore, this paper aims at filling the gap in research, and explores several factors predicting job satisfaction among emerging adults in Alberta, Canada.

Emerging adulthood marks an important point in the life of an individual. Arnett (2000) asserted that the period of life extending from age 18 to 25 be regarded as a distinctive life stage called 'emerging adulthood'. According to Arnett (2001), emerging adulthood occurs only when they are financially independent, are no longer living at home, have reached their educational aspirations, are comfortable with embracing the roles of marital partner and parent, and are able to live self-sufficiently. This stage of life is crucial in shaping the life direction and social identity of individuals because they are yet to converge on a stable lifestyle. Since this is generally the early stage of a career of an individual, it may have a great impact in shaping a person's future accomplishments and lifestyle. In Canada, the percentage of employed people in this age category is quite large (see Table 1). Therefore, it requires empirical studies to identify the aspects influencing job satisfaction of this particular group of individuals.

Lopez (1982) explored the differential impact of self-esteem on the relationships between various job satisfaction scores (e.g. overall, intrinsic, extrinsic, pay) and job performance, but found no significant correlations between the three 
self-esteem measures and the job satisfaction scale. In a study focusing on aspects of job experiences and self-esteem, Walsh and Taylor (1980) examined the association of work-related factors and various indicators of self-esteem for seven work groups, i.e., garbage-collectors, park workers, bartenders, barbers, mail carriers, high-school teachers and university professors. Walsh and Taylor (1980) found that job prestige had a positive influence on occupational self-esteem; although job prestige accounted for only about four percent of the variance in 'global' self-esteem, suggesting that low status jobs produce serious negative psycho-social consequences. A study by Abraham (1999) investigated the relationship between differential inequity, job satisfaction, intention to turn over, and self-esteem involving more than one occupational group. Abraham (1999) hypothesized that individuals with low self-esteem experience greater job dissatisfaction than those with high self-esteem, and found that self-esteem significantly moderated the global inequity-job satisfaction and global inequity-intention to turnover relationships.

Judge, Locke, Durham, and Kluger (1998) found that the four traits- self-esteem, generalized self-efficacy, locus of control, and neuroticism - were each independently significantly correlated with job satisfaction. In addition, Judge et al. (1998) argued that generalized self-efficacy should affect job satisfaction through its association with practical success on the job. In another study, Alavi and Askaripur (2003) found that there is a significant relationship between self-esteem and job satisfaction of personnel in the organization, that is, personnel with high self-esteem had more satisfaction in their jobs than personnel with low self-esteem. Therefore, the following hypothesis is proposed:

$\mathrm{H}_{1}$ : Self-esteem will have a direct positive association with job satisfaction.

Valued job characteristics indicate the attitude of individuals concerning the nature of work environment and related issues that describe the job they hold. Similar to the concept of valued job characteristics, previous research shows positive relationship between work values and job satisfaction. For instance, Robert Knoop (1994) asserted that work values significantly predicted job satisfaction. Hence, it is proposed that:

$\mathrm{H}_{2}$ : Valued job characteristics will have a direct positive association with job satisfaction.

Several studies suggested that job satisfaction and general happiness are positively related. Research indicated that happy individuals are relatively more successful in the workplace. For example, happiness is related to income (Diener \& Biswas-Diener, 2002), and getting social support from colleagues and supervisors (Iverson, Olekalns, \& Erwin, 1998). Most importantly, research provides evidence that happy people are more satisfied with their jobs compared with unhappy people (Connolly \& Viswesvaran, 2000; Judge \& Ilies, 2004). Happy people are also less likely to lose their jobs and to be unemployed than less happy people (Diener, Nickerson, Lucas, \& Sandvik, 2002). In an extensive review, Boehm and Lyubomirsky (2008) illustrated that happy people are more satisfied with their jobs and report having greater autonomy in their duties. It is therefore proposed that:

$\mathrm{H}_{3 a}$ : Happiness will be positively related to job satisfaction.

$\mathrm{H}_{3 \mathrm{~b}}$ : Happiness will positively lead to self-esteem, which in turn will positively lead to job satisfaction.

Work-reward preferences among individuals may or may not contribute to job satisfaction. Previous research found no significant differences in work-related preferences between US and Australian MBA students and industrial employees (Popp \& Davis, 1984). In addition, there were no significant cultural or regional differences found in work reward preferences (Popp \& Davis, 1984). Therefore, it is assumed that work-reward preferences may not be directly associated with job satisfaction, but rather could be mediated by other variables. Therefore, the proposed hypothesis is:

$\mathrm{H}_{4}$ : Work reward preferences will have a positive association with valued job characteristics, which will lead to job satisfaction.

Income has been found to be an important source of satisfaction at work. A number of studies have shown that income is related to job satisfaction (Sokoya, 2000; Sweeney et al., 1990). For instance, in a study comparing job satisfaction of public and private managers, Howard and Frink (1996) found that income was related to job satisfaction. In a similar study examining personal predictors of job satisfaction among 350 public sector managers, Sokoya (2000) found that income was a major source of job satisfaction. In addition, self-consistency theory suggests that individuals will seek out clear indications of their occupational success, and those who have high levels of income will perceive income as an important indication of their self-worth (Gecas \& Seff, 1990). Furthermore, Rosenberg and Pearlin (1978) noted that because economic achievement is an indicator of status in society, higher levels of economic achievement should lead to higher self-esteem. Therefore, the following two hypotheses are proposed:

$\mathrm{H}_{5 \mathrm{a}}$ : Income will have a direct positive association with job satisfaction.

$\mathrm{H}_{5 \mathrm{~b}}$ : Income will be positively related to self-esteem, which will lead to job satisfaction.

Educational credentials are vital for obtaining high position in a job. Studies have found positive relationships between education levels and job satisfaction (Al-Ajmi, 2006; Okpara, 2004). In addition, Glenn and Weaver (1982) found that the total effect of education was positive for both male and female, but was considerably stronger for women than for men. Hence, it is proposed that: 
$\mathrm{H}_{6}$ : Education will have a positive association with job satisfaction.

Gender differences in job satisfaction have also been extensively researched, but no conclusive evidence has been found with regard to the levels of satisfaction among men and women. For instance, Oshagbemi (2000) stated that research reported no significant difference between the sexes in relation to job satisfaction, particularly when a number of other variables were statistically controlled. However, results of the studies concerning satisfaction showed that gender was a significant predictor of job satisfaction (Bilgic, 1998). In addition, studies on gender earnings gap indicated that although women are paid less, they appear more satisfied with their jobs compared to men (Clark, 1997; Sloane \& Williams, 2000). It is therefore proposed:

$\mathrm{H}_{7}$ : There will be differences in job satisfaction between male and female.

\subsection{The Current Study}

Although research indicated that the association between age and job satisfaction is U-shaped (Clark, Oswald, \& Warr, 1996), there has been limited focus on research about emerging adults' job satisfaction in Canada in general, and Alberta in particular. According to Statistics Canada's Alberta Labor Force Statistics, in August 2009, Alberta has the highest employment rate (70.1\%) among provinces in Canada. In particular, the labor force participation rate among the emerging adults in Alberta is also one of the highest in Canada (see Table 1). It can be inferred from Table 1 that there is significant presence of emerging adults in the labor force in Alberta in August 2009, which is higher than it was in the previous year. Therefore, it is important to examine the aspect of satisfaction with jobs and career, and the predictors of job satisfaction among the emerging adults in Alberta.

[Insert Table 1 here]

\section{Methods}

\subsection{Data and Sample}

The data for the present study are obtained from the 2003 Alberta High School Graduate Survey conducted by the Population Research Laboratory (PRL), University of Alberta, as part of the School-Work Transition project. In the summer (April 30 to July 25) of 2003, 1,218 participants from across Alberta, Canada, completed telephone interviews and self-administered questionnaires. The survey used a cluster sampling strategy to construct a representative sample of Albertans. The data were weighted to compensate for the over-sampling of a large city (Edmonton) schools within the province, and to correct for smaller or larger than targeted sub-samples in other regions. A total of 1,175 interviews were completed by telephone, each averaging 32 minutes in length. In addition, 153 "paper and pencil" questionnaires were sent to potential respondents. Forty-three mail questionnaires were returned and added to the main database, creating a final sample of 1,218 survey respondents. The response rate was $62 \%$. Of the respondents, 1,030 were employed; and only employed respondents constituted the final sample in the study. The weighted survey estimates are used in the data analyses.

The research design for this study was developed with careful attention to ethical consideration. A University of Alberta Research Ethics Committee examined the content of the questionnaire and the planned data collection strategy prior to actual data collection for the study. The committee agreed with the research team's assessment that the questions to be asked were not intrusive nor overly sensitive, and that the potential value of the study out-weighted any inconvenience caused to potential participants. The informed consent from participants was obtained and participation was voluntary, and confidentiality of responses was maintained.

\subsection{Measures}

Job Satisfaction. Job Satisfaction was the dependent variable, and was measured by asking two questions, a) "How satisfied are you with your job?", and b) "How satisfied are you with your career to this point?". Participants rated these items on a scale from 1 (very dissatisfied) to 5 (very satisfied) $(M=3.64, S D=0.93)$. The two items formed a one-dimensional scale, with a Cronbach's alpha of 0.72 , which indicated good internal consistency reliability for a two-item scale. The scale significantly correlated with other study variables (see Table 4). In addition, factor loadings were 0.88 for each of the items, which further provide evidence for construct validity of the scale. Although job satisfaction consists of two items only, similar scale has been frequently used in previous studies (Heslop, Smith, Metcalfe, Macleod, \& Hart, 2002; Salmela-Aro \& Nurmi, 2007; Wanous, Reichers, \& Hudy, 1997).

Self-esteem. Eight items from the 10-item scale developed by Rosenberg (1989) were used to assess self-esteem. This scale is a self-report measure of generalized feelings about the self. Participants indicated on a 5-point Likert scale $(1=$ strongly disagree, 5 = strongly agree) the extent to which they agree or disagree with statements such as, "I feel that I have a number of good qualities", and "All in all, I am inclined to feel that I am a failure" (reverse coded) $(M=4.01$, $S D=0.59$ ). The factor loadings of items ranged from 0.59 to 0.74 . The Cronbach's alpha coefficient for the 8 -item scale was 0.79 . 
Work reward preferences. Work reward preferences was measured by six items. Although the original survey contained 13 items, the rest of the items were deleted due to low factor loadings (<.50). Participants responded to these items (e.g., "Work that gives a feeling of accomplishment", "Work with opportunities to learn new things") on a 5-point Likert scale $(1=$ not at all important, $5=$ very important $)(M=4.58, S D=0.44)$. The factor loadings of items ranged from 0.52 to 0.76 . The Cronbach's alpha coefficient for the scale was 0.78 .

Valued job characteristics. Seven items were used to assess the concept of valued job characteristics. A few items from the original survey were deleted due to low factor loadings $(<.50)$. Participants indicated on a 5-point Likert scale $(1=$ strongly disagree, 5 = strongly agree) the extent to which they agree or disagree with statements such as, "My job lets me use my skills and abilities" and "My job requires that I work very hard" $(M=3.64, S D=0.90)$. The factor loadings of items ranged from 0.58 to 0.84 . The Cronbach's alpha coefficient for the scale was 0.85 .

Happiness. Happiness was elicited by the question "Thinking about your life in general, how happy are you with your life?". Response categories were $1=$ not happy at all, $2=$ somewhat happy, and $3=$ very happy. The response categories show that participants were generally happy $(M=2.62, S D=0.53)$. Although happiness consists of one item only, a similar scale has been used in previous research. Single-item measures of happiness are reliable, valid, and commonly used in community surveys, as well as in cross-cultural comparisons (Abdel-Khalek, 2006; Kahneman \& Krueger, 2006; Swinyard, Kau, \& Phua, 2001).

Income. Each participant was asked to identify, in Canadian dollars, the average amount of money received each month from income and salaries before any deductions. The average income received each month was about CAD $\$ 2,700($ Mean $=2762.52$, Median $=2,500, S D=1775.36)$.

Control variables. Gender was coded as 0 (male) or 1 (female). Age was coded as $1=$ up to 24 years, $2=25$ years, or 3 $=26+$ years. Marital status was coded as $0=$ not married (Single, divorced, widowed, and cohabiting) or $1=$ married . In the study, 18 participants (1.5\%) reported being divorced, 166 participants (13.7\%) reported cohabiting, and one reported being widowed. Education was indicated by the enrolment at post-secondary level studies: $0=n o$ or $1=y e s$. Occupational categories were coded as $1=$ management or professional, $2=$ skilled, or $3=$ semi-skilled and unskilled.

\subsection{Analysis}

The statistical analyses were performed in two steps. First, data were analyzed using SPSS 15.0, which included analysis of descriptive statistics (e.g., percentages, mean scores, standard deviations), and inferential statistics (e.g., $\chi^{2}$-test, $t$-test, $F$-test, Pearson's correlation coefficient, and linear regression analysis). Second, Structural Equation Modeling (SEM) was conducted by using AMOS 16.0 to assess fitness of the model based on the proposed hypotheses. AMOS utilizes the missing-data method that enables all the observations in the data set to be used in estimating the parameters of the model. Unlike other methods, this method does not assign values for those that are missing, but employs all the data that are available to estimate the model using the full information maximum likelihood (FIML). Since the data set of the study has multiple missing cases, it is particularly important to ensure the correctness of the analyses.

\section{Results}

\subsection{Profile of Survey Participants}

Fifty three percent (645) of the participants were male and 47 percent (573) of them were female. The average age of these respondents was 25 years (Mean $=25, S D=1$ ). About two-thirds of them $(76 \%$ ) were not married (single, divorced or cohabiting). Majority of them (88\%) attended in post-secondary level education (technical college, university, or diploma) and among those who attended university (583 participants, 54.7\%), 67.2 percent obtained a bachelor degree. Majority of them (85.4\%) are currently employed (either in one job [71.6\%] or in several jobs [13.8\%]). Among the employed, 36.8 percent of them were in management or professional categories, 39.8 percent of them were in skilled category, and 23.4 percent of them were in semi-skilled and unskilled categories. Although quite similar percentage of male and females were employed in management or professional categories, more men were employed in skilled category, while more women were employed in semi-skilled and unskilled categories. More than two-thirds of the participants earned below CAD $\$ 4,000$ per month. Among the participants, men earned more than women did (not shown here).

\subsection{Job Satisfaction}

Table 2 demonstrates the level of job satisfaction among the participants. Compare to women (58.3\%), men were slightly more satisfied with their job (65.9\%); the difference was statistically significant $\left(\chi^{2}(2)=11.85, p<.01\right)$. Regardless of age differences, married individuals were more satisfied with their job (66.9\%) compared to non-married one $(60.4 \%)$; the difference was statistically significant $\left(\chi^{2}(2)=7.03, p<.05\right)$. Although level of education did not significantly differ in terms of job satisfaction, individuals holding management or professional job categories showed more satisfaction with their job (68.4\%) compared to two other categories; the difference was statistically significant $\left(\chi^{2}\right.$ 
$(4)=15.49, p<.01)$. Those who earned more were more satisfied with their job $(78.1 \%)$, the difference was statistically significant $\left(\chi^{2}(4)=38.39, p<.001\right)$. In a similar fashion, those who were very happy were more satisfied with their job $(71.9 \%)$, the difference was statistically significant $\left(\chi^{2}(4)=1.07, p<.001\right)$.

[Insert Table 2 here]

\subsection{Gender Difference in Job Satisfaction}

An independent samples $t$-test was conducted to evaluate the hypothesis that the male and female participants differ in terms of their mean attitude towards job satisfaction. It can be observed from Table 3 that both the groups had approximately the same sample size (male $n=512$, women $n=519$ ), which indicates the fulfillment of one of the principle assumptions of the independent sample $t$-test. However, it was surprising to find that the result was not significant, $t(1029)=1.49, p=0.14$. Although the chi-square test was significant (see Table 2) in terms of gender differences on job satisfaction, this independent sample $t$-test showed it to be otherwise. These conflicting findings might be explained by the fact that in Table 2, the response categories for job satisfaction were collapsed into three in order to adjust the sample requirement for cross-tabulation. However, since the study constructed the job satisfaction variable containing 5 response categories, when the original response categories were used to analyze gender differences, it resulted in non-significance. Therefore, hypothesis 7 had to be rejected.

[Insert Table 3 here]

Table 4 presents the descriptive statistics and intercorrelations among the study variables. In the case of job satisfaction, the significant correlations ranged in magnitude from $r=0.15(p<.001)$ for work reward preferences to a high of $r=$ $0.69(p<.001)$ for valued job characteristics. In the case of self-esteem, the significant correlations ranged in magnitude from $r=0.17(p<.001)$ for work reward preferences to a high of $r=0.52(p<.001)$ for happiness. Work reward preferences significantly correlated with valued job characteristics $(r=0.30, p<.001)$, and with happiness $(r=0.08(p$ $<.05)$. Valued job characteristics significantly correlated with all other study variables, ranging from $r=0.24(p<.001)$ to a high of $r=0.69(p<.001)$. Occupational categories significantly correlated with all other study variables except for work reward preferences. Happiness significantly correlated with all other study variables, ranging from $r=0.08(p$ $<.05)$ to a high of $r=0.52(p<.001)$. Finally, monthly income significantly correlated with all other study variables (except for work reward preferences), ranging in magnitude from $r=0.13(p<.001)$ for happiness to a high of $r=0.31$ $(p<.001)$ for job satisfaction.

[Insert Table 4 here]

\subsection{Linear Regression Results and Interaction Effect}

Two linear regression analyses were conducted to examine the predictive value of the study variables and to test the interaction effect between the two specific study variables. Results shown in Table 5 illustrate weak to moderately high predictive relationship of the independent variables with the dependent variable. Self-esteem significantly predicted job satisfaction $(\beta=0.26, p<.001)$. Similarly, valued job characteristics significantly led to higher job satisfaction $(\beta=$ $0.54, p<.001)$. Happiness significantly predicted job satisfaction $(\beta=0.12, p<.001)$. Monthly income significantly predicted job satisfaction among participants $(\beta=0.06, p<.05)$.

However, an unexpected finding was that work reward preferences had a negative significant association with job satisfaction $(\beta=-0.05, p<.05)$. Among the control variables, only marital status significantly (negatively) predicted job satisfaction $(\beta=-0.05, p<.05)$. It indicates that non-married participants had higher job satisfaction. However, gender $(\beta=-0.03, p=.12)$, age, occupational categories, and education $(\beta=-0.02, p=.27)$ were found to be non-significant. Therefore, Hypothesis 6 had to be rejected. Thus, controlling for gender, age, marital status, occupational categories, and education, the results demonstrated that approximately $58 \%$ of the variances of job satisfaction were explained by the independent variables in the model (Adj. $\left.R^{2}=.583\right)$, and the model was statistically significant $(F=135.74, p$ $<.001)$.

\section{[Insert Table 5 here]}

Since marital status significantly predicted job satisfaction but gender did not, it was important to examine whether there were any interaction effect between gender and martial status on job satisfaction. It was found (not shown here) that the interaction effect was not significant $(\beta=0.09, p=.25)$. However, by incorporating the interaction variable, the impact of marital status was no longer significant $(\beta=-0.12, p=.06)$. Therefore, both self-esteem and valued job characteristics remained the strongest predictors of job satisfaction.

\subsection{Structural Equation Modeling}

Structural Equation Modeling (SEM) was conducted by using AMOS 16.0 to assess fitness of the path model based on the proposed hypotheses. As indicated before, the psychometric adequacy of these scales, such as their unidimensionality, is typically evaluated by methods outside of the scope of the structural equation model - usually by the attainment of sufficiently high internal-consistency reliabilities, high item-total correlations, or by high factor 
loadings from an exploratory factor analysis - all of which are less rigorous methods than that provided by a SEM analysis (Gerbing \& Anderson, 1988). More importantly, SEM is a combination of factor analysis and path analysis, and allows a more 'causal' explanation of findings (Byrne, 2001).

There are several criteria set by the SEM scholars to assess the fitness of a model. Hu and Bentler (1999) suggest that for a model to have a good fit, the comparative fit index (CFI) and the Tucker-Lewis index (TLI) should be greater than 0.95 , and the root mean square error of approximation (RMSEA) should be less than 0.06. The RMSEA examines the probability of close model fit and is considered a more appropriate test, as it has been shown to be less affected by sample size (Byrne, 2001; Floyd \& Widaman, 1995). The lower the discrepancy measured by the RMSEA the better, with RMSEA $=0.0$ indicating a perfect fit. The CFI, a revised version of the Bentler-Bonett (Bentler \& Bonnett, 1980) normed fit index that adjusts for degrees of freedom $(d f)$, ranges in value from 0 to 1.00 . Acceptable values are CFI $>$ 0.90 , and a value of about $>0.08$ for the RMSEA indicates a reasonable error of approximation (Arbuckle, 2007, p. 592). James Arbuckle (2007) asserted that all the measures of the normed fit index (NFI), relative fit index (RFI), incremental fit index (IFI), the Tucker-Lewis coefficient also known as the Bentler-Bonett non-normed fit index (NNFI) tend to range between 0 and 1 , with values close to 1 indicating a good fit. Kline (2004) and Byrne (2001) also suggested that a good fitting model generally has a $\chi^{2} / \mathrm{df}$ ratio of less than 3.0 as a measure of minimum sample discrepancy.

In this study, the model fit was assessed using the following reported fit indices: chi-square, $\chi^{2} / \mathrm{df}$ ratio, the root mean square error of approximation (RMSEA), the normed fit index (NFI), relative fit index (RFI), incremental fit index (IFI), the Tucker-Lewis coefficient or the non-normed fit index (NNFI), and the Comparative Fit Index (CFI). Multicollinearity was also assessed by calculating the squared multiple correlations between each variable and all the rest with values greater than 0.90 being of concern (Kline, 2004). There was not issues of multicollinearity, as the highest value identified in squared multiple correlations between variables was $\beta=0.52$. As shown in the previous analyses, the hypotheses 6 and 7 were non-significant; and therefore, were excluded from the SEM model.

Results obtained from the structural equation modeling are presented in Table 6 and Figure 1. The overall fit indices suggested a good fit of the model to the data: $\mathrm{CFI}=0.998, \mathrm{RMSEA}=0.026, \chi^{2}=5.57, d f=2, \chi^{2} / \mathrm{df}=2.79, \mathrm{TLI} / \mathrm{NNFI}=$ $0.978, \mathrm{NFI}=0.997, \mathrm{RFI}=0.966$, and IFI $=0.998$ (see Table 6). As suggested by the literature, CFI and NFI were close to perfect fit. Similarly, RMSEA was 0.03 , which falls well below the cut-off points recommended by Hu and Bentler (1999), indicating acceptable model fit. In addition, the $\chi^{2} / \mathrm{df}$ ratio was below the cut-off point established by Kline (2004) and Byrne (2001).

\section{[Insert Table 6 here]}

The results presented in Figure 1 showed the predictability of the independent variables to the dependent variable. Hypothesis 1 stated that self-esteem will have a direct positive association with job satisfaction, and the hypothesis was supported $(\beta=0.28, p<.001)$. Hypothesis 2 was also supported, valued job characteristics had a direct positive association with job satisfaction, $\beta=0.52, p<.001$. Hypothesis $3 \mathrm{a}$ asserted that happiness will be positively related to job satisfaction. The hypothesis was supported $(\beta=0.11, p<.01)$. Similarly, hypothesis $3 \mathrm{~b}$ was also supported, Happiness positively led to self-esteem $(\beta=0.48, p<.001)$, which in turn positively led to job satisfaction $(\beta=0.28, p$ $<.001)$. Hypothesis 4 suggested that work reward preferences will have a positive association with valued job characteristics, which will lead to job satisfaction. The hypothesis was supported, as work reward preferences was positively related to valued job characteristics $(\beta=0.25, p<.001)$, which led to job satisfaction $(\beta=0.52, p<.001)$.

[Insert Figure 1 here]

Hypothesis $5 \mathrm{a}$ was weakly supported, as income had a direct positive association with job satisfaction $(\beta=0.08, p$ $<.05)$. Finally, hypothesis $5 \mathrm{~b}$ predicted that income will be positively related to self-esteem, which will lead to job satisfaction. The hypothesis was also supported, income had a positive association with self-esteem $(\beta=0.22, p<.001)$, which led to job satisfaction $(\beta=0.28, p<.001)$. Another interesting finding emerged, which was not previously hypothesized, was that self-esteem predicted values job characteristics $(\beta=0.35, p<.001)$, which led to job satisfaction $(\beta=0.52, p<.001)$. In the final model, approximately $59 \%$ of the variances of job satisfaction were explained by the independent variables (squared multiple correlations or standardized $R^{2}=.59$ ).

\section{Discussion and Conclusion}

The primary aim of the study was to explore the extent of satisfaction with jobs and career, and the predictors of job satisfaction among the emerging adults in Alberta. The study found, as predicted, that self-esteem was directly related to job satisfaction. This is consistent with findings from previous research (Alavi \& Askaripur, 2003; Judge, Locke, Durham, \& Kluger, 1998; Lopez, 1982). Likewise, valued job characteristics strongly predicted job satisfaction, similar to Knoop's (1994) findings. Furthermore, as expected, happiness significantly predicted job satisfaction, which is consistent with the existing literature (Boehm \& Lyubomirsky, 2008; Connolly \& Viswesvaran, 2000; Judge \& Ilies, 
2004). In was interesting to note that happiness also predicted self-esteem, which in turn led to job satisfaction. These psychosocial traits are important in understanding job satisfaction among the emerging adults in Alberta.

The analyses also highlighted that income was a predictor of job satisfaction, although the predictive value was statistically weak, but significant. The results are consistent with the previous findings (Sokoya, 2000; Sweeney et al., 1990). In addition, income was highly associated with self-esteem, which in turn led to job satisfaction among the participants. It is also similar to the findings of previous research (Gecas \& Seff, 1990; Rosenberg \& Pearlin, 1978). However, work-reward preferences did not exhibit direct relationship with job satisfaction, but rather was mediated by self-esteem and valued job characteristics, leading to job satisfaction. This indicates that better work-reward preference reinforce self-esteem leading to more job satisfaction.

However, contrary to other research, which found positive relationships between education levels and job satisfaction (Al-Ajmi, 2006; Okpara, 2004), this study found the opposite: education did not predict job satisfaction. This can be explained by the existing theories. The human capital theory posits that higher education generally leads to better quality jobs, resulting in increased job satisfaction (Krahn, Lowe, \& Hughes, 2007, p. 434). On the other hand, highly educated employees working in less-rewarding jobs will experience depleted job satisfaction (Krahn et al. 2007). Furthermore, this study did not find gender differences in terms of job satisfaction among male and female. In addition, gender did not predict job satisfaction. The effect of marital status did also disappear when the interaction effect of gender and marital status was assessed. Since the age structure of this group of people was quite similar, there was no difference in terms of their satisfaction with job. This implies that other personality traits are more important than just the demographic features shaping job satisfaction among the emerging adults.

Several key points summarize the main findings of the study. First, the structural equation model develop in the study had a high predictive value, which accounted for explaining about $60 \%$ of the variance of the dependent variable. It fitted the data very well. The model showed that self-esteem and valued job characteristics were the two most significant predictors of job satisfaction. The model is important in understanding the dynamics of the predictive value of the study variables leading to job satisfaction. However, future research should include more psychosocial variables (e.g., stress, hopefulness, depression, social support) in the study to examine the impact of those variables on job satisfaction. Second, the job satisfaction among the emerging adults in Alberta shows similar patterns with the other adult population when taking into account of the findings of the previous research. It would be interesting to examine the cross-cultural differences in terms of job satisfaction among the emerging adults across continents. Third, this study is distinctive in its nature in exploring the job satisfaction among the emerging adults in Alberta, which has been neglected by the researchers so far.

Previous studies assist us to interpret the findings of this research and to identify areas for future study. Except for differences in terms of gender and education, most of the findings in this study were in tune with the previous research conducted across the world. The findings suggest that although lots of research has been done on job satisfaction among different categories of people, more research is needed to understand the pattern of job satisfaction among the emerging adults.

\subsection{Limitation and Future Direction}

Despite its strengths, the study has several limitations. First, the model developed in the study is an initial attempt in understanding job satisfaction among emerging adults in Alberta. Clearly, there is a need to replicate the results of the study among other groups. Second, the study uses two items in measuring job satisfaction. Although there are a few research celebrating a one-item measure of job satisfaction, it is also important to examine the impact of a multidimensional scale of job satisfaction that covers the psychological (e.g., personality and behavioral dimension, individual differences), social and cultural (e.g., relationships in the workplace), economic structure, and work environment-specific, social status, class, and ethnic groups, and occupational prestige dimensions in the response items. For instance, researchers can employ widely used and reliable instruments such as the Job Description Index (JDI). Similarly, happiness was measured by a single item. Future research could benefit from employing multidimensional scale that can capture the subjective, general, situational, broader, and culture specific facets of happiness. Third, the study was conducted in Alberta. Future studies can explore job satisfaction among emerging adults across Canada and around the world. Forth, the study limits itself with cross-sectional analysis of panel data. Future studies can look into the changes of job satisfaction across life-cycle. Fifth, the study used cluster sampling technique. Future research should use more random sampling for better generalizability. Obviously, repeated investigation of linkages among a broader set of variables would permit richer examination in future studies. Sixth, future research can address the question of why educational status and occupational categories do not appear to affect job satisfaction as expected.

\subsection{Policy Implications}

The present findings lead the researcher to suggest that employers should conduct programs that would reinforce the self-esteem of the employees; because high self-esteem would direct to high job satisfaction, culminating in more 
productivity in the workplace. Although job dissatisfaction may not always result in quitting behavior (Hammer \& Avgar, 2005), it may turn into employee deviance and reduced work ethic, e.g., absenteeism, calling in sick etc. (Hulin, 1991), which can ultimately translate into reduced productivity among employees in the workplace. The organizations can benefit from enhanced productivity, and the employees would be rewarded socio-economically, and would enjoy better psychological health. In addition, the organizations should ensure friendly work environment for their employees, which will lead to better job satisfaction and benefit to the organization and the society at large. In summary, one of the best ways to increase job satisfaction of an organization's employees is to enhance their self-esteem.

\section{References}

Abdel-Khalek, A. M. (2006). Measuring happiness with a single item scale. Social Behavior and Personality, 34(2), 139-149.

Abraham, R. (1999). The relationship between differential inequity, job satisfaction, intention to turn over, and self-esteem. The Journal of Psychology, 133(2), 205-211.

Al-Ajmi, R. (2006). The effect of gender on job satisfaction and organizational commitment in Kuwait. International Journal of Management, 23(4), 838-844.

Alavi, H. R., \& Askaripur, M. R. (2003). The relationship between self-esteem and job satisfaction of personnel in government organizations. Public Personnel Management, 32(4), 591-600.

Arbuckle, J. L. (2007). Amos 16.0 User's Guide. Chicago, IL: SPSS, Inc.

Arnett, J. J. (2000). Emerging adulthood: A theory of development from the late teens through the twenties. American Psychologist, 55, 469-480.

Arnett, J. J. (2001). Conceptions of the transition to adulthood: Perspectives from adolescence through midlife. Journal of Adult Development, 8, 133-143.

Bentler P. M., \& Bonnett D. G. (1980). Significance tests and goodness of fit in the analysis of covariance structures. Psychological Bulletin, 88, 588-606.

Bilgic, R. (1998). The relationship between job satisfaction and personal characteristic of Turkish workers. The Journal of Psychology, 132, 549-57.

Boehm, J. K., \& Lyubomirsky, S. (2008). Does happiness promote career success? Journal of Career Assessment, 16(1), 101-116.

Byrne, B. (2001). Structural equation modeling with AMOS: Basic concepts, applications, and programming. Mahwah, NJ: Lawrence Erlbaum.

Clark, A. E. (1997). Job satisfaction and gender: Why are women so happy at work? Labour Economics, 4(4), 341-372.

Clark, A., Oswald, A., \& Warr, P. (1996). Is job satisfaction U-shaped in age? Journal of Occupational and Organizational Psychology, 69, 57-81.

Connolly, J. J., \& Viswesvaran, C. (2000). The role of affectivity in job satisfaction: A meta-analysis. Personality and Individual Differences, 29, 265-281.

Cranny, C. J., Smith, P. C., and Stone, E. F. (1992). Job satisfaction: How people feel about their jobs and how it affects their performance. New York, NY: Lexington Books.

Diener, E., \& Biswas-Diener, R. (2002). Will money increase subjective well-being? A literature review and guide to needed research. Social Indicators Research, 57, 119-169.

Diener, E., Nickerson, C., Lucas, R. E., \& Sandvik, E. (2002). Dispositional affect and job outcomes. Social Indicators Research, 59, 229-259.

Floyd F. J., \& Widaman K. F. (1995). Factor analysis in the development and refinement of clinical assessment instruments. Psychological Assessment, 7, 286-299.

Gecas, V., \& Seff, M. (1990). Social class and self-esteem: Psychological centrality, compensation, and the relative effects of work and home. Social Psychology Quarterly, 53, 165-173.

Gerbing, D., \& Anderson, J. (1988). An updated paradigm for scale development incorporating unidimensionality and its assessment. Journal of Marketing Research, 25, 186-192.

Glenn, N. D., \& Weaver, C. N. (1982). Further evidence on education and job satisfaction. Social Forces, 61, 46-55.

Hammer, T. H., \& Avgar, A. (2005). The impact of unions on job satisfaction, organizational commitment, and turnover. Journal of Labor Research, 26(2), 241-266. 
Haviland, S. (2004). Job satisfaction and the gender paradox: An international perspective. Paper presented at the annual meeting of the American Sociological Association, San Francisco, CA, August 14, 2004.

Heslop, P., Smith, G. D., Metcalfe, C., Macleod, J., \& Hart, C. (2002). Change in job satisfaction and its association with self-reported stress, cardiovascular risk factors and mortality. Social Science \& Medicine, 54, 1589-1599.

Howard, J., \& Frink, D. (1996). The effects of organizational restructure on employee satisfaction. Group and Organizational Management, 21, 278-303.

Hu, L., \& Bentler, P. M. (1999). Cutoff criteria for fit indexes in covariance structure analysis: Conventional criteria versus new alternatives. Structural Equation Modeling, 6(1), 1-55.

Hulin, C. L. (1991). Adaptation, persistence, and commitment in organizations. In M. D. Marvin \& L. M. Hough (Eds.), Handbook of industrial and organizational psychology, $2^{\text {nd }}$ ed., Vol. 2 (pp. 445-505). Palo Alto, CA: Consulting Psychologists Press.

Iverson, R. D., Olekalns, M., \& Erwin, P. J. (1998). Affectivity, organizational stressors, and absenteeism: A causal model of burnout and its consequences. Journal of Vocational Behavior, 52, 1-23.

Judge, T. A., \& Ilies, R. (2004). Affect and job satisfaction: A study of their relationship at work and at home. Journal of Applied Psychology, 4, 661-673.

Judge, T. A., Locke, E. A., Durham, C. C., \& Kluger, A. N. (1998). Dispositional effects on job and life satisfaction: The role of core evaluations. Journal of Applied Psychology, 83, 17-34.

Kahneman, D., \& Krueger, A. B. (2006). Developments in the measurement of subjective well-being. Journal of Economic Perspectives, 20(1), 3-24.

Kline, R. (1998). Principles and practice of structural equation modeling. New York: Guilford Press.

Knoop, R. (1994). Work values and job satisfaction. Journal of Psychology, 128(6), 683-690.

Krahn, H. J., Lowe, G. S., \& Hughes, K. D. (2007). Work, industry, and Canadian society (5 ${ }^{\text {th }}$ ed.). Toronto, ON: Thomson-Nelson.

Krahn, H., Lowe, G. S., \& Lehmann, W. (2002). Acquisition of employability skills by high school students. Canadian Public Policy, 28(2), 275-296.

Lopez, E. M. (1982). A test of the self-consistency theory of job performance-job satisfaction relationship. Academy of Management Journal, 25(2), 335-348.

Okpara, J. O. (2004). Personal characteristics as predictors of job satisfaction. Information Technology \& People, 17(3), 327-338.

Oshagbemi, T. (2000). Gender differences in the job satisfaction of university teachers. Women in Management Review, 15(7), 331-343.

Popp, G. E., \& Davis, H. J. (1984). American and Australian work reward preference patterns. Asia Pacific Journal of Management, 2(1), 62-64.

Rosenberg, M. (1989). Society and the adolescent self-image (Rev. ed.). Middletown CT: Wesleyan University Press.

Rosenberg, M., \& Pearlin, L.I. (1978). Social class and self-esteem among children and adults. American Journal of Sociology, 84, 53-77.

Salmela-Aro, K., \& Nurmi, J. (2007). Self-esteem during university studies predicts career characteristics 10 years later. Journal of Vocational Behavior, 70, 463-477.

Sekaran, U. (1986). Self-esteem and sense of competence as moderators of the job satisfaction of professionals in dual career families. Journal of Occupational Behaviour, 7, 341-344.

Sloane, P. J., \& Williams, H. (2000). Job satisfaction, comparison earnings and gender. Labour, 14(3), 473-502.

Sokoya, S. K. (2000). Personal predictors of job satisfaction for the public sector manager: Implications for management practice and development in a developing economy. Journal of Business in Developing Nations, 4, article 1. Retrieved August 20, 2009, [Online] Available: http://www.ewp.rpi.edu/jbdn/jbdnv401.htm

Sweeney, P. D., McFarin, D. B., \& Inderrieden, E. J. (1990). Using relative deprivation theory to explain satisfaction with income and pay level: A multi-study examination. Academy of Management Journal, 33, 423-36.

Swinyard, W. R., Kau, A. K., \& Phua, H. Y. (2001). Happiness, materialism, and religious experience in the US and Singapore. Journal of Happiness Studies, 2, 13-32. 
Walsh, E. J., \& Taylor, M. C. (1980). Occupational correlates of multidimensional self-esteem: comparisons among garbage-collectors, bartenders, professors, and other workers. The Pennsylvania State University Journal, 66 (3), $252-268$.

Wanous, J. P., Reichers, A. E., \& Hudy, M. J. (1997). Overall job satisfaction: How good are single-item measures? Journal of Applied Psychology, 82, 247-252.

Table 1. Labor force characteristics by Age and Gender in Alberta (seasonally adjusted)

\begin{tabular}{|c|c|c|}
\hline & August 2009 & August 2008 \\
\hline & \multicolumn{2}{|c|}{ In thousands (except rates) } \\
\hline \multicolumn{3}{|c|}{ Both genders, 15 to 24 years } \\
\hline Population & 508.3 & 503.9 \\
\hline Labor force & 348.1 & 365.5 \\
\hline Unemployment rate & 13.6 & 7.4 \\
\hline Employment rate & 59.2 & 67.2 \\
\hline \multicolumn{3}{|c|}{ Both genders, 25 years and above } \\
\hline Population & $1,637.3$ & $1,599.0$ \\
\hline Labor force & $1,445.0$ & $1,408.3$ \\
\hline Unemployment rate & 5.8 & 2.5 \\
\hline Employment rate & 83.2 & 85.8 \\
\hline \multicolumn{3}{|l|}{ Men, 15 to 24 years } \\
\hline Population & 263.4 & 260.5 \\
\hline Labor force & 183.0 & 195.7 \\
\hline Unemployment rate & 15.5 & 9.1 \\
\hline Employment rate & 58.7 & 68.3 \\
\hline \multicolumn{3}{|c|}{ Women, 15 to 24 years } \\
\hline Population & 244.9 & 243.4 \\
\hline Labor force & 165.2 & 169.8 \\
\hline Unemployment rate & 11.4 & 5.4 \\
\hline Employment rate & 59.8 & 66.0 \\
\hline \multicolumn{3}{|c|}{ Men, 25 years and above } \\
\hline Population & 845.4 & 821.8 \\
\hline Labor force & 796.3 & 772.7 \\
\hline Unemployment rate & 6.3 & 1.9 \\
\hline Employment rate & 88.2 & 92.2 \\
\hline \multicolumn{3}{|c|}{ Women, 25 years and above } \\
\hline Population & 791.9 & 777.2 \\
\hline Labor force & 648.7 & 635.6 \\
\hline Unemployment rate & 5.1 & 3.4 \\
\hline Employment rate & 77.8 & 79.0 \\
\hline
\end{tabular}

Source: Statistics Canada, Labour Force Survey, CANSIM Table 2820001 
Table 2. Job Satisfaction* by Demographic Characteristics

\begin{tabular}{llll}
\hline Variables & (\%) Dissatisfied & (\%) Neutral & (\%) Satisfied
\end{tabular}

\section{Total}

Gender **

Male

Female

Age

Up to 24

25 years

$26+$ years

Marital status **

Married

Not-married

Education

7.1

13.2

11.6

25.3

63.2

11.5

13.0

25.8

62.6

27.9

59.1
Post-secondary

No post-secondary

Occupation **

Management/professional

7.9

Skilled

12.7

15.8

Semi- and unskilled

Monthly Income **

Up to $\$ 2000$
$\$ 2001$ to $\$ 4000$

$\$ 4001$ and above

11.5

13.3

.9

23.7

68.4

27.0

60.3

29.6

54.6

Note: $n=1,030$

* Respondents answered on a scale of 'very dissatisfied' (1) to (5) 'very satisfied'. In this table, values of 1 and 2 are combined into 'dissatisfied' while values of 4 and 5 are combined into 'satisfied' to adjust the sample requirement for cross-tabulation purposes.

** Differences between sub-groups are statistically significant $\left(\chi^{2}, p<.05\right)$. 
Table 3. Mean Attitude Scores and Standard Deviations on Job Satisfaction by Gender

\begin{tabular}{lllllll}
\hline Gender & $n$ & $M$ & $S D$ & SE Mean & $t$ & $p$ \\
\hline Male & 512 & 3.69 & .94 & .042 & & \\
& & & & & 1.49 & .14 \\
Female & 519 & 3.60 & .92 & .040 & & \\
\hline
\end{tabular}

Note: $F \overline{(1030)=0.13}$

Table 4. Descriptive Statistics and Intercorrelations for the Job Satisfaction Measures

\begin{tabular}{|c|c|c|c|c|c|c|c|}
\hline Variables & 1 & 2 & 3 & 4 & 5 & 6 & 7 \\
\hline 1. Job satisfaction ${ }^{1}$ & - & $.56^{* *}$ & $.15 * *$ & $.69 * *$ & $-.31 * *$ & $.38 * *$ & $.31 * *$ \\
\hline 2. Self-esteem ${ }^{2}$ & & . & $.17 * *$ & $.42 * *$ & $-.20 * *$ & $.52 * *$ & $.29 * *$ \\
\hline 3. Work reward preferences ${ }^{3}$ & & & - & $.30 * *$ & -.04 & $08 *$ & -.03 \\
\hline 4. Valued job characteristics ${ }^{2}$ & & & & - & $-.40 * *$ & $.24 * *$ & $.28 * *$ \\
\hline 5. Occupational categories ${ }^{4}$ & & & & & - & $-.10^{*}$ & $-.24 * *$ \\
\hline 6. Happiness ${ }^{5}$ & & & & & & $\ldots$ & $.13 * *$ \\
\hline 7. Monthly income & & & & & & & - \\
\hline Cronbach's Alpha & .718 & .794 & .783 & .847 & - & - & - \\
\hline Mean & 3.64 & 4.01 & 4.58 & 3.64 & 2.07 & 2.62 & 2762.52 \\
\hline Standard Deviation & .93 & .59 & .44 & .90 & .81 & .53 & 1775.36 \\
\hline
\end{tabular}

Note: Sample sizes for above correlations ranged between 988 and 1,030. Sample data is weighted.

$* p<.01, * * p<.001$

1. Measured on a 5-point Likert scale, where $1=$ 'very dissatisfied' and $5=$ 'very satisfied'.

2. Measured on a 5-point Likert scale, where $1=$ 'strongly disagree' and $5=$ 'strongly agree'.

3. Measured on a 5-point Likert scale, where $1=$ 'not at all important' and $5=$ 'very important'.

4. Coded as 1 = 'management and professional', $2=$ 'skilled', and $3=$ 'semi-/unskilled'.

5. Coded as $1=$ 'not at all happy' and 3 = 'very happy'. 
Table 5. Regression Analysis Results: Predictor and Control Variables’ Effects on Job Satisfaction

\begin{tabular}{llcll}
\hline Variables & $b$ & $S E$ & $\beta$ & $t$ \\
\hline Constant & -.08 & .26 & -.32
\end{tabular}

Predictor variables

\begin{tabular}{lllll} 
Self-esteem & .42 & .04 & .26 & $9.78^{* * *}$ \\
Work reward preferences & -.11 & .05 & -.05 & $-2.28^{*}$ \\
Valued job characteristics & .56 & .03 & .54 & $20.89 * * *$ \\
Happiness & .23 & .04 & .12 & $5.10^{* * *}$ \\
Monthly income & 3.15 & .00 & .06 & $2.56^{*}$ \\
& & & \\
Control variables & & & -1.57 \\
Gender (female $=1$, male $=0)$ & -.07 & .04 & -.03 & .12 \\
Age & .004 & .03 & .002 & $-2.51 *$ \\
Marital status (married $=1)$ & -.06 & .03 & -.05 & -.60 \\
Occupational categories & -.02 & .03 & -.01 & -1.09 \\
Education (post-secondary, yes $=1)$ & -.07 & .06 & -.02 & \\
R & .766 & & & \\
Adj. $R^{2}$ & .583 & & & \\
$F$-value & $135.74 * * *$ & & & \\
\hline
\end{tabular}

$* p<.05, * * * p<.001$

There were no issues of multicollinearity in this model: the highest VIF score was 1.63.

Table 6. Fit Indices for Structural Equation Modeling (SEM): Job Satisfaction Model

\begin{tabular}{lllllllll}
\hline$\chi^{2}$ & $d f$ & $\chi^{2} / d f$ & RMSEA & NFI & RFI & IFI & NNFI/TLI & CFI \\
5.6 & 2 & 2.79 & .026 & .997 & .966 & .998 & .978 & .998 \\
\hline
\end{tabular}

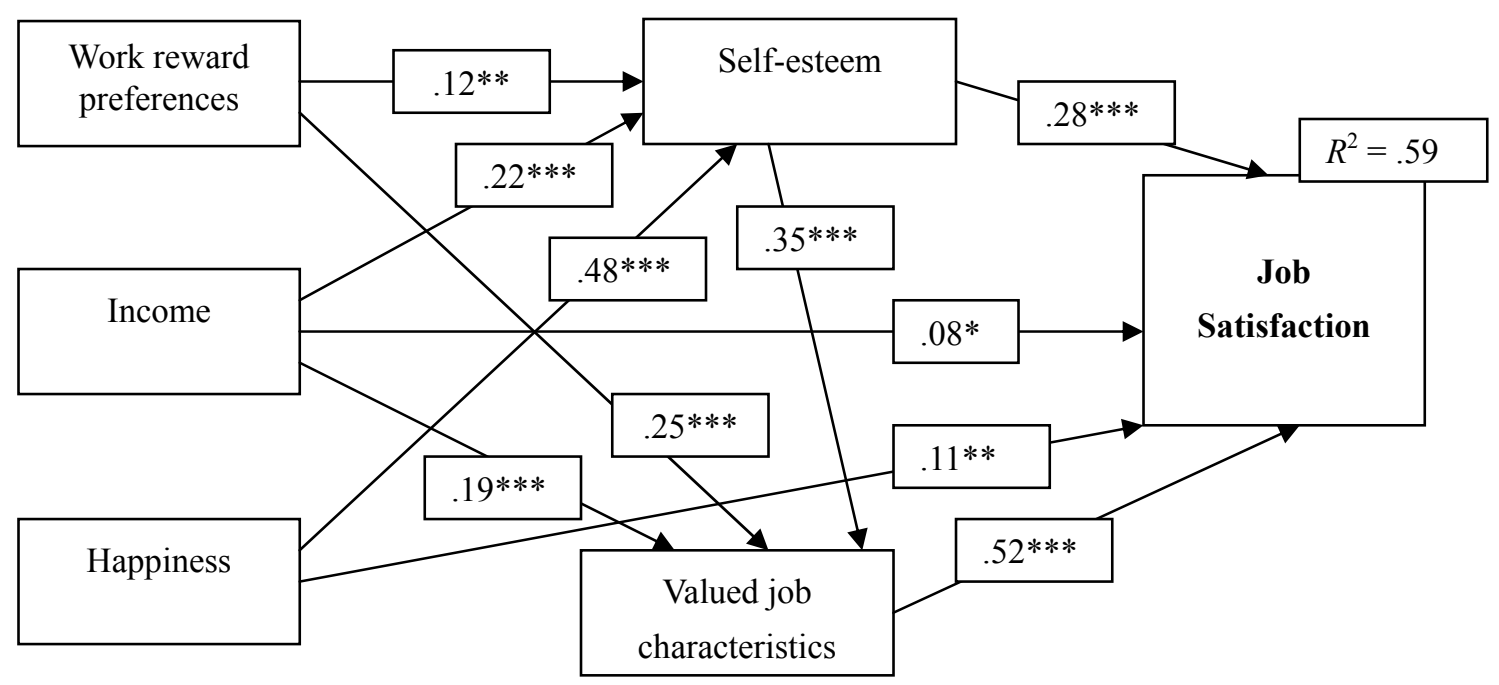

Figure 1.

Figure 1: The observed path model (SEM) of Job Satisfaction. The model illustrates the predictor variables for job satisfaction: Work reward preferences, income, happiness, self-esteem, and values job characteristics. Coefficients are standardized Beta's.

$* p<.05, * * p<.01, * * * p<.001$. Standardized $R^{2}=.59$. 